\section{A Combinational Approach Using Cell Therapy, Tissue Engineering, and Distracting Device for the Treatment of Degenerative Disc Disease}

\author{
Christina McKee ${ }^{1,2}$, Mick Perez-Cruet ${ }^{2,3,4}$ and G Rasul \\ Chaudhry ${ }^{1,2 *}$
}

${ }^{1}$ Department of Biological Sciences, Oakland University, Rochester, Michigan, 48309, USA

${ }^{2} \mathrm{OU}-W B$ Institute for Stem Cell and Regenerative Medicine, Rochester, Michigan, 48309, USA

${ }^{3}$ OUWB School of Medicine, Oakland University, Rochester, Michigan, 48309, USA

${ }^{4}$ Department of Neurosurgery, Beaumont Health System, Royal Oak, Michigan, 48073, USA

\section{Commentary}

The Intervertebral Disc (IVD) is a fibrocartilaginous tissue instrumental in spine flexibility, allowing for the bending and twisting motion between vertebral bodies. Degenerative Disc Disease (DDD) results from the complex and chronic deterioration in IVD organization, structure, and function [1]. DDD has been implicated in the majority of cases of chronic Lower Back Pain (LBP) [2]. LBP is one of the most prevalent and debilitating musculoskeletal diseases, affecting nearly $80 \%$ of Americans during their lifetime [3]. Consequently, IVD degeneration accounts for around $25 \%-30 \%$ of all direct and indirect healthcare costs in North America and Europe [4]. In the United States alone, an estimated $\$ 84.1$ billion to $\$ 624.8$ billion has been spent annually for the treatment of LBP. In addition, a loss of between $\$ 7.4$ billion to $\$ 28$ billion annually has been reported from diminished work productivity [5]. As such, there is a great deal of interest in elucidating the etiology of DDD and relieving the

*Corresponding author: G Rasul Chaudhry, Department of Biological Sciences, Oakland University, Rochester, Michigan, 48309 USA, Tel: +1 2483703350; Fax: +1 2483703586; E-mail: chaudhry@oakland.edu

Citation: McKee C, Perez-Cruet M, Chaudhry GR (2021) A Combinational Approach Using Cell Therapy, Tissue Engineering, and Distracting Device for the Treatment of Degenerative Disc Disease. J Stem Cell Res Dev Ther 7: 064.

Received: February 11, 2021; Accepted: February 18, 2021; Published: February 25, 2021

Copyright: (c) 2021 McKee C, et al. This is an open-access article distributed under the terms of the Creative Commons Attribution License, which permits unrestricted use, distribution, and reproduction in any medium, provided the original author and source are credited. expansive societal burden associated with DDD. Toward this end, it is important to understand the biology and function of IVD as well as the intrinsic and extrinsic factors associated with degeneration.

The IVD is composed of an inner highly hydrated Nucleus Pulposus (NP) tissue, which is surrounded by an outer collagen-rich Annulus Fibrosus (AF) and flanked by cartilaginous endplates [6]. The AF is characterized by its high tensile strength [7], providing protection to the gelatinous NP, which is responsible for the shockabsorbing and weight-bearing cushioning of spinal loads [8]. Multiple factors have been implicated in IVD degeneration, including altered mechanical loading, nutrient deficiency, changes in cellular deposition and hereditary factors [9-12]. Degenerative changes in the NP are characterized by the replacement of NP progenitors, notochordal disc cells, with Chondrocyte-Like Cells (CLCs), resulting in the loss of osmotic properties and Extracellular Matrix (ECM) integrity, leading to the formation of fibrocartilage tissue [13]. These age-related cellular and ECM changes negatively impact the biomechanical capabilities of the IVD, and subsequent trauma can lead to further structural damage of the tissue [8]. Due in part to a lack of vascularization and cellularization [14], cells within the NP account for only approximately $1 \%$ of the total volume of the IVD [13] and as a result, the IVD has little to no regenerative capacity [7].

Currently, there is no effective treatment for DDD and/or chronic LBP. In general, treatments address symptomatic pain management using analgesics and physiotherapy [7,15]. In severe cases, aggressive surgical procedures such as discectomy and spinal fusion are performed; however, these interventions are highly invasive and often lead to reduced IVD and spine function [7]. Therefore, recent efforts have focused on cell therapy to aid in IVD regeneration by addressing the underlying cause of DDD. While pre-clinical and clinical studies have indicated that cell transplantation is feasible, debate on the optimal cell source as well as the mechanism/vehicle of delivery still exists [16-18].

Early attempts at treating DDD using allogenic articular chondrocytes isolated from juvenile tissue showed promising results with improvement in reported LBP in small-scale preliminary studies, although the majority of radiographic measurements did not indicate significant improvement [19]. In early phase I clinical trials, transplantation of NOVOCART Disk plus, autologous chondrocytes derived from IVD cells, indicated no beneficial improvement but no adverse effects; phase II studies are estimated to be completed in 2021, following 5 years of observation, and may provide more information on long-term functional improvement [20]. However, a major limitation of these studies is the use of chondrocytes cells, which are difficult to isolate and expand to the numbers needed for therapeutic applications [21]. Additionally, chondrocytes, which are considered to be end differentiated cells are not felt to contribute to the production of extracellular proteoglycans or Glycosaminoglycans (GAG), which is largely responsible for the water holding capacity of the IVD [22]. Therefore, the effectiveness of these cells in restoring the degenerated desiccated disc to normal functional hydration is 
Citation: McKee C, Perez-Cruet M, Chaudhry GR (2021) A Combinational Approach Using Cell Therapy, Tissue Engineering, and Distracting Device for the Treatment of Degenerative Disc Disease. J Stem Cell Res Dev Ther 7: 064.

questionable. Consequently, numerous clinical studies have focused on Mesenchymal Stem Cells (MSCs). These cells are multipotent and self-renewing stem cells that can be isolated from a variety of adult tissues [23]. In general, the majority of clinical trials have utilized bone marrow derived MSCs (BM-MSCs) for transplantation into degenerated IVDs and have reported outcomes ranging from no palliative relief to reduced pain and improved disc hydration [24-27]. The inconsistency of these results may be in part due to the variability of isolated BM-MSCs. MSCs from adult sources are often invasively isolated in low quantities with cell quality correlated to donor age $[28,29]$. As a result, we have focused our research on the therapeutic use of primitive MSCs isolated from perinatal tissues [30,31]. These cells can be non-invasively harvested from discarded umbilical cord and placenta following birth and have shown enhanced growth potential, allowing for the production of the large number of cells needed for preclinical and clinical studies.

In our lab, we have isolated primitive MSCs from a unique niche of the umbilical cord tissue, which has shown high proliferative capability compared to BM-MSCs [31]. These umbilical cord derived MSCs are capable of differentiation into chondroprogenitor cells [30-32]. In fact, we observed that differentiation of primitive MSCs into chondroprogenitor cells prior to transplantation improved their regenerative capacity in a rabbit model of DDD [32]. Transplanted cells survived, integrated, and dispersed in the damaged areas of the $\mathrm{NP}$ and were functionally active expressing human chondrogenic genes, $S O X 9$, ACAN and COL2 [32]. These chondroprogenitor cells also produced NP matrix proteins including sulfated GAG (sGAGs), and improved histological and water content properties of the degenerated IVD [32]. In a subsequent study, we further optimized in vitro differentiation of primitive MSCs into NP-like Cells (NPCs), expressing chondrogenic and acknowledged NP specific markers [33-35] including, FOXF1, KRT19, PAX6, CA12 and COMP [36] In agreement with our previous studies, differentiated cells showed improved efficacy over MSCs when injected into degenerated rabbit IVDs. NPC transplantation enhanced ECM accumulation and cellularity in the augmented NP, which exhibited improved physicochemical characteristics including sGAG, NP content, and disc hydration [36]. Overall, these findings further emphasize the importance of both cell source and lineage differentiation in the regeneration of damaged IVDs by addressing the etiology of the disease. However, the overall success of cell transplantation in clinical studies has been shown to also be limited by the propensity of cell leakage from the site of injection [37-39] and failure to reestablish mechanical function by restoration of disc height $[7,15,40]$.

Consequently, tissue engineering techniques utilizing biocompatible materials have recently garnered enthusiasm due to their ability to promote mechanical stability in degenerated IVDs in DDD animal models [41]. Transplantation of whole xenograft IVD constructs require highly invasive medical interventions, which can result in additional structural IVD damage [42-44]. Therefore, we and others have focused our studies on the use of injectable hydrogel scaffolds, which mimic the fully hydrated native NP and can form at the site of injury $[2,15,45]$. It is imperative to employ biomaterials with the mechanical strength to support spine loading, as well as support IVD cell growth and differentiation.

Using an ex vivo model of DDD, we have demonstrated the successful injection of cells using self-assembling scaffolds comprised of two synthetic and biocompatible Polyethylene Glycol (PEG) polymers functionalized with acrylate (PEG-4-Acr) and thiol end (PEG-4-SH) group [46]. These polymers self-assemble via Michael addition reaction forming chemically cross-linked hydrogels, capable of forming at the site of injection in situ. Our results showed that the PEG-4-Acr/PEG-4-SH self-assembling scaffolds promoted retention of injected cells in the IVD without leakage. More importantly, we observed that transplantation of MSCs with the PEG-4-Acr/PEG4-SH scaffolds improved MSC differentiation into NPCs. This confirmed our in vitro studies, which showed that 3-D culture of MSCs in the PEG self-assembling scaffolds promoted differentiation into a NP lineage without the need for inductive media [46]. Injection of MSCs with the self-assembling scaffolds also resulted in significant improvement in structural integrity and cellularity of the NP of degenerated IVD explants when compared to cells or scaffolds alone. IVD explants injected with MSCs using the self-assembling scaffolds displayed higher ECM production of proteoglycans, glycoproteins, and sGAG at levels resembling healthy NP. Transplantation of cells together with the self-assembling scaffold also led to upregulation of NP specific markers, including FOXF1, K19 and VIMENTIN, known to be associated with NP cells.

Overall, these findings support the use of a novel multi-pronged treatment strategy, allowing for 1) transplantation of highly proliferative and primitive MSCs with minimal manipulation in vitro; 2) increased cell retention upon injection at the site of injury; and 3) highly specified differentiation into NPCs capable of producing NP markers and ECM for regeneration of damaged IVD tissue. Additional clinical studies are warranted to optimize the mechanical properties of injectable scaffolds and its effect on disc height and palliative treatment.

While the self-assembling scaffold may mimic the elastic and hydrated properties of native NP tissue, it may not provide enough mechanical support to allow for complete restoration of disc height in degenerated IVDs. This could be addressed with the help of a pedicle screw based minimally invasive distractive medical devices to provide the space needed to allow for both successful cell integration and regeneration of disc. This proprietary device (Annulo ${ }^{\mathrm{TM}}$ ) was designed to allow for a gradual distraction of the disc space. By applying a motion sparing distractive forces to the disc, over time the disc can be restored to its natural height, mimicking the action of tissue expanders, which allow for the gradual generation of new skin for skin grafting procedures when placed under the skin $[47,48]$. After the disc height is restored, NP derived MSC scaffolds can be injected into the NP to restore its function, therefore returning the degenerated collapsed disc to its normal functional capacity. As such, the temporary use of an IVD distracting device, such as the Annulo ${ }^{\mathrm{TM}}$ technology, may supplement cellular therapy and aid in the restoration of both the biological and mechanical function of the IVD. Such intertransdisciplinary approaches should be investigated in preclinical and clinical studies, thus facilitating bench-to-basic science research in collaboration with clinical product development to improve patient outcomes. These studies could provide proof-of-concept for combinational use of self-assembling scaffolds for the delivery of cells and a distracting device via minimally invasive surgery to maintain disc height, thus providing a regenerative environment for the treatment of DDD. 
Citation: McKee C, Perez-Cruet M, Chaudhry GR (2021) A Combinational Approach Using Cell Therapy, Tissue Engineering, and Distracting Device for the Treatment of Degenerative Disc Disease. J Stem Cell Res Dev Ther 7: 064.

\section{Acknowledgements}

The study was supported by the OU-WB Institute for Stem Cell and Regenerative Medicine (ISCRM), Oakland University, and Michigan Head and Spine Institute. C. McKee received the Provost Graduate Research Award from Oakland University for this project.

\section{References}

1. Sobajima S, Vadala G, Shimer A, Kim JS, Gilbertson LG, et al. (2008) Feasibility of a stem cell therapy for intervertebral disc degeneration. Spine J 8: 888-896.

2. Chou AI, Reza AT, Nicoll SB (2008) Distinct intervertebral disc cell populations adopt similar phenotypes in three-dimensional culture. Tissue Eng Part A 14: 2079-2087.

3. Waddell G (1996) Low back pain: a twentieth century health care enigma. Spine (Phila Pa 1976) 21: 2820-2825.

4. Whitehurst DG, Bryan S, Lewis M, Hill J, Hay EM (2012) Exploring the cost-utility of stratified primary care management for low back pain compared with current best practice within risk-defined subgroups. Ann Rheum Dis 71: 1796-1802.

5. Gore M, Sadosky A, Stacey BR, Tai KS, Leslie D (2012) The burden of chronic low back pain: clinical comorbidities, treatment patterns, and health care costs in usual care settings. Spine (Phila Pa 1976) 37: 668-677.

6. Rutges J, Creemers LB, Dhert W, Milz S, Sakai D, et al. (2010) Grad, Variations in gene and protein expression in human nucleus pulposus in comparison with annulus fibrosus and cartilage cells: potential associations with aging and degeneration. Osteoarthritis Cartilage 18: 416-423.

7. Wan Y, Feng G, Shen FH, Laurencin CT, Li X (2008) Biphasic scaffold for annulus fibrosus tissue regeneration. Biomaterials 29: 643-652.

8. Melrose J (2002) Disc structure function and its potential for repair. APLAR Journal of Rheumatology 5: A7-A8.

9. Ohshima H, Urban JP, Bergel DH (1995) Effect of static load on matrix synthesis rates in the intervertebral disc measured in vitro by a new perfusion technique. J Orth Res 13: 22-29.

10. Urban JPG, Smith S, Fairbank JCT (2004) Nutrition of the intervertebral disc. Spine (Phila Pa 1976) 29: 2700-2709.

11. Battie MC, Videman T (2006) Lumbar disc degeneration: Epidemiology and genetics. J Bone Joint Surg Am 88: 3-9.

12. Adams MA, Roughley PJ (2006) What is intervertebral disc degeneration, and what causes it? Spine (Phila Pa 1976) 31: 2151-2161.

13. Renani HB, Ghorbani M, Beni BH, Karimi Z, Mirhosseini M, et al. (2012) Determination and comparison of specifics of nucleus pulposus cells of human intervertebral disc in alginate and chitosan-gelatin scaffolds. Advanced biomedical research 1: 81 .

14. Gilson A, Dreger M, Urban JP (2010) Differential expression level of cytokeratin 8 in cells of the bovine nucleus pulposus complicates the search for specific intervertebral disc cell markers. Arthritis Res Ther 12: R24.

15. Henriksson HB, Svanvik T, Jonsson M, Hagman M, Horn M, et al. (2009) Transplantation of human mesenchymal stems cells into intervertebral discs in a xenogeneic porcine model. Spine (Phila Pa 1976) 34: 141-148.

16. Binch ALA, Fitzgerald JC, Growney EA, Barry F (2021) Cell-based strategies for IVD repair: Clinical progress and translational obstacles. Nat Rev Rheumatol 2021.

17. Sakai D, Schol J (2017) Cell therapy for intervertebral disc repair: Clinical perspective. J Orthop Translat 9: 8-18.

18. Tong W, Lu Z, Qin L, Mauck RL, Smith HE, et al. (2017) Cell therapy for the degenerating intervertebral disc. Transl Res 181: 49-58.
19. Coric D, Pettine K, Sumich A, Boltes MO (2013) Prospective study of disc repair with allogeneic chondrocytes presented at the 2012 Joint Spine Section Meeting. J Neurosurg Spine 18: 85-95.

20. Tschugg, Michnacs F, Strowitzki M, Meisel HJ, Thomé C (2016) A prospective multicenter phase I/II clinical trial to evaluate safety and efficacy of NOVOCART Disc plus autologous disc chondrocyte transplantation in the treatment of nucleotomized and degenerative lumbar disc to avoid secondary disease: Study protocol for a randomized controlled trial. Trials 17: 108 .

21. Vinatier C, Guicheux J (2016) Cartilage tissue engineering: From biomaterials and stem cells to osteoarthritis treatments. Ann Phys Rehabil Med 59: 139-144.

22. Mwale F, Roughley P, Antoniou J (2004) Distinction between the extracellular matrix of the nucleus pulposus and hyaline cartilage: A requisite for tissue engineering of intervertebral disc. Eur Cell Mater 8: 58-63.

23. Macrin D, Joseph JP, Pillai AA, Devi A (2017) Eminent Sources of Adult Mesenchymal Stem Cells and Their Therapeutic Imminence. Stem Cell Rev Rep 13: 741-756.

24. Elabd C, Centeno CJ, Schultz JR, Lutz G, Ichim T, et al. (2016) Intra-discal injection of autologous, hypoxic cultured bone marrow-derived mesenchymal stem cells in five patients with chronic lower back pain: a longterm safety and feasibility study. J Transl Med 14: 253.

25. Orozco L, Soler R, Morera C, Alberca M, Sanchez A, et al. (2011) Intervertebral disc repair by autologous mesenchymal bone marrow cells: A pilot study. Transplantation 92: 822-828.

26. Pettine KA, Murphy MB, Suzuki RK, Sand TT (2015) Percutaneous injection of autologous bone marrow concentrate cells significantly reduces lumbar discogenic pain through 12 months. Stem Cells 33: 146-156.

27. Yoshikawa T, Ueda Y, Miyazaki K, Koizumi M, Takakura Y (2010) Disc regeneration therapy using marrow mesenchymal cell transplantation: a report of two case studies. Spine (Phila Pa 1976) 35: 475-480.

28. Bentivegna A, Miloso M, Riva G, Foudah D, Butta V, et al. (2013) DNA Methylation Changes during In Vitro Propagation of Human Mesenchymal Stem Cells: Implications for Their Genomic Stability? Stem Cells Int 2013: 192425 .

29. Teschendorff AE, Jones A, Fiegl H, Sargent A, Zhuang JJ, et al. (2012) Epigenetic variability in cells of normal cytology is associated with the risk of future morphological transformation. Genome Med 4: 24.

30. Beeravolu N, Khan I, McKee C, Dinda S, Thibodeau B, et al. (2016) Isolation and comparative analysis of potential stem/progenitor cells from different regions of human umbilical cord. Stem Cell Res 16: 696-711.

31. Beeravolu N, McKee C, Alamri A, Mikhael S, Brown C, et al. (2017) Isolation and Characterization of Mesenchymal Stromal Cells from Human Umbilical Cord and Fetal Placenta. J Vis Exp 122: 55224.

32. Beeravolu N, Brougham J, Khan I, McKee C, Perez-Cruet M, et al. (2016) Human Umbilical Cord Derivatives Regenerate Intervertebral Disc. J Tissue Eng Regen Med 12: 579-591.

33. Han XB, Zhang YL, Li HY, Chen B, Chang X, et al. (2015) Differentiation of Human Ligamentum Flavum Stem Cells Toward Nucleus Pulposus-Like Cells Induced by Coculture System and Hypoxia, Spine (Phila $\mathrm{Pa}$ 1976) 40: 665-674.

34. Minogue BM, Richardson SM, Zeef LA, Freemont AJ, Hoyland JA (2010) Characterization of the human nucleus pulposus cell phenotype and evaluation of novel marker gene expression to define adult stem cell differentiation, Arthritis Rheum 62: 3695-3705.

35. Rodrigues-Pinto R, Richardson SM, Hoyland JA (2013) Identification of novel nucleus pulposus markers: Interspecies variations and implications for cell-based therapiesfor intervertebral disc degeneration. Bone Joint Res 2: $169-178$. 
Citation: McKee C, Perez-Cruet M, Chaudhry GR (2021) A Combinational Approach Using Cell Therapy, Tissue Engineering, and Distracting Device for the Treatment of Degenerative Disc Disease. J Stem Cell Res Dev Ther 7: 064.

- Page 4 of 5 •

36. Perez-Cruet M, Beeravolu N, McKee C, Brougham J, Khan I, et al. (2018) Potential of Human Nucleus Pulposus-Like Cells Derived From Umbilical Cord to Treat Degenerative Disc Disease. Neurosurgery 84: 272-283.

37. Bertram H, Kroeber M, Wang H, Unglaub F, Guehring T, et al. (2005) Matrix-assisted cell transfer for intervertebral disc cell therapy. Biochem Biophys Res Commun 331: 1185-1192.

38. Kalaf EAG, Pendyala M, Bledsoe JG, Sell SA (2017) Characterization and restoration of degenerated IVD function with an injectable, in situ gelling alginate hydrogel: An in vitro and ex vivo study. J Mech Behav Biomed Mater 72: 229-240.

39. Omlor GW, Bertram H, Kleinschmidt K, Fischer F, Brohm K, et al. (2010) Methods to monitor distribution and metabolic activity of mesenchymal stem cells following in vivo injection into nucleotomized porcine intervertebral discs. Eur Spine J 19: 601-612.

40. Ahn J, Park EM, Kim BJ, Kim JS, Choi B, et al. Transplantation of human Wharton's jelly-derived mesenchymal stem cells highly expressing TGFbeta receptors in a rabbit model of disc degeneration. Stem Cell Res Ther 6: 190.

41. Huang YC, Hu Y, Li Z, Luk KDK (2018) Biomaterials for intervertebral disc regeneration: Current status and looming challenges. J Tissue Eng Regen Med 12: 2188-2202.

42. Hensley A, Rames J, Casler V, Rood C, Walters J, et al. (2018) Decellularization and characterization of a whole intervertebral disk xenograft scaffold. J Biomed Mater Res A 106: 2412-2423.
43. Park SH, Gil ES, Cho H, Mandal BB, Tien LW, et al. (2012) Intervertebral disk tissue engineering using biphasic silk composite scaffolds. Tissue Eng Part A 18: 447-458.

44. Zeng C, Yang Q, Zhu M, Du L, Zhang J, et al. (2014) Silk fibroin porous scaffolds for nucleus pulposus tissue engineering. Mater Sci Eng C 37: 232-240.

45. Leckie SK, Sowa GA, Bechara BP, Hartman RA, Coelho JP, et al. (2013) Injection of human umbilical tissue-derived cells into the nucleus pulposus alters the course of intervertebral disc degeneration in vivo. Spine J 13: 263-272.

46. McKee C, Beeravolu N, Brown C, Perez-Cruet M, Chaudhry GR (2020) Mesenchymal stem cells transplanted with self-assembling scaffolds differentiated to regenerate nucleus pulposus in an ex vivo model of degenerative disc disease. Applied Materials Today 18: 100474.

47. Johnson GR, Han P, Giacopelli JA (1992) Tissue expansion as an alternative to skin grafting for closure of skin deficits. J Am Podiatr Med Assoc 82: 249-259.

48. Kumar G, Narayan B (2014) The Tension-Stress Effect on the Genesis and Growth of Tissues: Part II. The Influence of the Rate and Frequency of Distraction, in: Banaszkiewicz P, Kader D (Eds.), Classic Papers in Orthopaedics, Springer London, UK, Pg No's: 523-525. 


\section{di

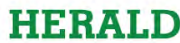

Advances In Industrial Biotechnology | ISSN: 2639-5665

Advances In Microbiology Research | ISSN: 2689-694X

Archives Of Surgery And Surgical Education | ISSN: 2689-3126

Archives Of Urology

Archives Of Zoological Studies | ISSN: 2640-7779

Current Trends Medical And Biological Engineering

International Journal Of Case Reports And Therapeutic Studies | ISSN: 2689-310X

Journal Of Addiction \& Addictive Disorders | ISSN: 2578-7276

Journal Of Agronomy \& Agricultural Science | ISSN: 2689-8292

Journal Of AIDS Clinical Research \& STDs | ISSN: 2572-7370

Journal Of Alcoholism Drug Abuse \& Substance Dependence | ISSN: 2572-9594

Journal Of Allergy Disorders \& Therapy | ISSN: 2470-749X

Journal Of Alternative Complementary \& Integrative Medicine | ISSN: 2470-7562

Journal Of Alzheimers \& Neurodegenerative Diseases | ISSN: 2572-9608

Journal Of Anesthesia \& Clinical Care | ISSN: 2378-8879

Journal Of Angiology \& Vascular Surgery | ISSN: 2572-7397

Journal Of Animal Research \& Veterinary Science | ISSN: 2639-375

Journal Of Aquaculture \& Fisheries | ISSN: 2576-5523

Journal Of Atmospheric \& Earth Sciences | ISSN: 2689-8780

Journal Of Biotech Research \& Biochemistry

Journal Of Brain \& Neuroscience Research

Journal Of Cancer Biology \& Treatment | ISSN: 2470-7546

Journal Of Cardiology Study \& Research | ISSN: 2640-768X

Journal Of Cell Biology \& Cell Metabolism | ISSN: 2381-1943

Journal Of Clinical Dermatology \& Therapy | ISSN: 2378-8771

Journal Of Clinical Immunology \& Immunotherapy | ISSN: 2378-8844

Journal Of Clinical Studies \& Medical Case Reports | ISSN: 2378-8801

Journal Of Community Medicine \& Public Health Care | ISSN: 2381-1978

Journal Of Cytology \& Tissue Biology | ISSN: 2378-9107

Journal Of Dairy Research \& Technology | ISSN: 2688-9315

Journal Of Dentistry Oral Health \& Cosmesis | ISSN: 2473-6783

Journal Of Diabetes \& Metabolic Disorders | ISSN: 2381-201X

Journal Of Emergency Medicine Trauma \& Surgical Care | ISSN: 2378-8798

Journal Of Environmental Science Current Research | ISSN: 2643-5020

Journal Of Food Science \& Nutrition | ISSN: 2470-1076

Journal Of Forensic Legal \& Investigative Sciences | ISSN: 2473-733X

Journal Of Gastroenterology \& Hepatology Research | ISSN: 2574-2566
Journal Of Genetics \& Genomic Sciences | ISSN: 2574-2485

Journal Of Gerontology \& Geriatric Medicine | ISSN: 2381-8662

Journal Of Hematology Blood Transfusion \& Disorders | ISSN: 2572-2999

Journal Of Hospice \& Palliative Medical Care

Journal Of Human Endocrinology | ISSN: 2572-9640

Journal Of Infectious \& Non Infectious Diseases | ISSN: 2381-8654

Journal Of Internal Medicine \& Primary Healthcare | ISSN: 2574-2493

Journal Of Light \& Laser Current Trends

Journal Of Medicine Study \& Research | ISSN: 2639-5657

Journal Of Modern Chemical Sciences

Journal Of Nanotechnology Nanomedicine \& Nanobiotechnology | ISSN: 2381-2044

Journal Of Neonatology \& Clinical Pediatrics | ISSN: 2378-878X

Journal Of Nephrology \& Renal Therapy | ISSN: 2473-7313

Journal Of Non Invasive Vascular Investigation | ISSN: 2572-7400

Journal Of Nuclear Medicine Radiology \& Radiation Therapy | ISSN: 2572-7419

Journal Of Obesity \& Weight Loss | ISSN: 2473-7372

Journal Of Ophthalmology \& Clinical Research | ISSN: 2378-8887

Journal Of Orthopedic Research \& Physiotherapy | ISSN: 2381-2052

Journal Of Otolaryngology Head \& Neck Surgery | ISSN: 2573-010X

Journal Of Pathology Clinical \& Medical Research

Journal Of Pharmacology Pharmaceutics \& Pharmacovigilance | ISSN: 2639-5649

Journal Of Physical Medicine Rehabilitation \& Disabilities | ISSN: 2381-8670

Journal Of Plant Science Current Research | ISSN: 2639-3743

Journal Of Practical \& Professional Nursing | ISSN: 2639-568

Journal Of Protein Research \& Bioinformatics

Journal Of Psychiatry Depression \& Anxiety | ISSN: 2573-0150

Journal Of Pulmonary Medicine \& Respiratory Research | ISSN: 2573-0177

Journal Of Reproductive Medicine Gynaecology \& Obstetrics | ISSN: 2574-2574

Journal Of Stem Cells Research Development \& Therapy | ISSN: 2381-2060

Journal Of Surgery Current Trends \& Innovations | ISSN: 2578-7284

Journal Of Toxicology Current Research | ISSN: 2639-3735

Journal Of Translational Science And Research

Journal Of Vaccines Research \& Vaccination | ISSN: 2573-0193

Journal Of Virology \& Antivirals

Sports Medicine And Injury Care Journal | ISSN: 2689-8829

Trends In Anatomy \& Physiology | ISSN: 2640-7752

Submit Your Manuscript: https://www.heraldopenaccess.us/submit-manuscript 